\title{
Incentivizing wellness through community supported agriculture: Reflections on shareholder impacts of an employer-based CSA voucher program
}

\author{
Jairus Rossi ${ }^{a}$ and Tim Woods ${ }^{b}$ \\ University of Kentucky
}

Submitted August 14, 2020 / Revised November 24, 2020, January 14, April 23, and June 28, 2021 /

Accepted July 2, 2021 / Published online November 18, 2021

Citation: Rossi, J., \& Woods, T. (2021). Incentivizing wellness through community supported agriculture:

Reflections on shareholder impacts of an employer-based CSA voucher program. Journal of Agriculture, Food

Systems, and Community Development, 11(1), 27-44. https://doi.org/10.5304/jafscd.2021.111.005

Copyright (C) 2021 by the Authors. Published by the Lyson Center for Civic Agriculture and Food Systems. Open access under CC-BY license.

\begin{abstract}
Community supported agriculture (CSA) programs are emerging as popular consumer options for produce acquisition. While many researchers have discussed the impacts of CSA on economies, communities, and the environment, others are interested in documenting how produce-based CSA shapes health. In this paper, we evaluate whether and to what extent CSA incentive programs, funded by diverse employer groups in central Kentucky 20152018, impact shareholder wellness. To evaluate impact, we use two distinct types of data: we compare shareholders' perceived frequency of food lifestyle behaviors from pre- and post-season sur-

a* Corresponding author: Jairus Rossi, Assistant Research Professor, Community and Economic Development Initiative of Kentucky, Department of Agricultural Economics, University of Kentucky; Lexington, KY 40546 USA; jairusrossi@uky.edu

b Timothy A. Woods, Extension Professor, Department of Agricultural Economics, University of Kentucky; Lexington, KY 40546 USA; tim.woods@,uky.edu
\end{abstract}

veys, and we examine anonymized medical claims from a subset of these participants to determine if CSA participation impacts short-run usage of medical services. From survey data, we observed statistically significant changes in some shareholder behaviors. For instance, CSA shareholders perceived that they consumed vegetable salads more often while decreasing their intake of processed foods and snacks. From medical claims data, shareholders are billed less in diet-related medical claims following CSA participation compared to a control group from the same employer organization. In short, we find that CSA is generally beneficial and participants view their experience as providing motivation to reshape their relationship to food. We conclude by offering strategies for institutions and organizations to effectively develop and support CSA incentive programs.

\section{Keywords}

Community Supported Agriculture, CSA Incentive Programs, Food Lifestyle Behaviors 


\section{Introduction}

Community supported agriculture (CSA) is a unique food subscription model. Individuals prepay or subscribe to receive regular shares in a farm harvest. While CSA is evolving to incorporate varied commitment lengths, payment structures, product offerings, and customization options, this food acquisition model generally involves a farm providing the subscriber (i.e., shareholder) with farm products (i.e., shares) at regular intervals for a set duration. CSAs often offer weekly or biweekly shares across different phases of the growing season. This iterative structure, across multiple months, is consequential, as a shareholder in a produce-based CSA will experience a constantly changing variety of vegetables in their shares throughout the growing season. Additionally, shareholders may be given a larger quantity of produce than what they would normally buy at the grocery store. Because of these characteristics, shareholders are consistently challenged to incorporate a broader array and quantity of produce into their meals. These challenges evolve with the growing season. The CSA model thus offers opportunities for shareholders to modify food lifestyle behaviors (Rossi et al., 2017), and may be compelling for organizations interested in promoting behavior changes related to food.

This purpose of this study is to determine whether and to what extent CSA provides benefits to shareholder wellbeing. While many researchers have illustrated CSA impacts on communities, environments, and economies (Galt, 2013; Hayden \& Buck, 2012; Hinrichs, 2000; Ostrom, 2007), an emerging research priority is to identify the potential of CSA to transform shareholders' relationships to food (Cohen et al., 2012; Rossi et al., 2017; Russell \& Zepeda,
2008; Vasquez et al., 2016; Wilkins et al., 2015). Consideration of CSA health impacts comes at a time when per capita medical costs in the United States have increased $\sim 40 \%$ over the past 15 years (Organisation for Economic Cooperation and Development [OECD], 2021). At our university, the trend is even more pronounced. In a sample of about 4500 employees enrolled in our university's Heath and Wellness program, per capita billed medical claims have increased rapidly over the past five years (Figure 1). For employers who provide health insurance coverage and need to restrain intensifying medical costs, CSA may provide one avenue for the improvement of organizational wellness.

In this study, we analyze four years of survey and medical claims data from participants in employer-sponsored CSA voucher programs in central Kentucky 2015-2018. Our analysis is guided by two research questions. First, we ask whether CSA shareholders perceive their food lifestyle behaviors to change following participation. Previously published results from the first year (2015) of this voucher program suggest that CSA participants observed changes in a broad variety of behaviors (Rossi et al., 2017). However, those results only included first-time shareholders in one employer program. We have expanded our participant pool to include multiple employer

\section{Figure 1. Per Capita Annual Billed Medical Claims: Comparison between U.S. Average and University of Kentucky Employees Enrolled in the Health and Wellness Program}

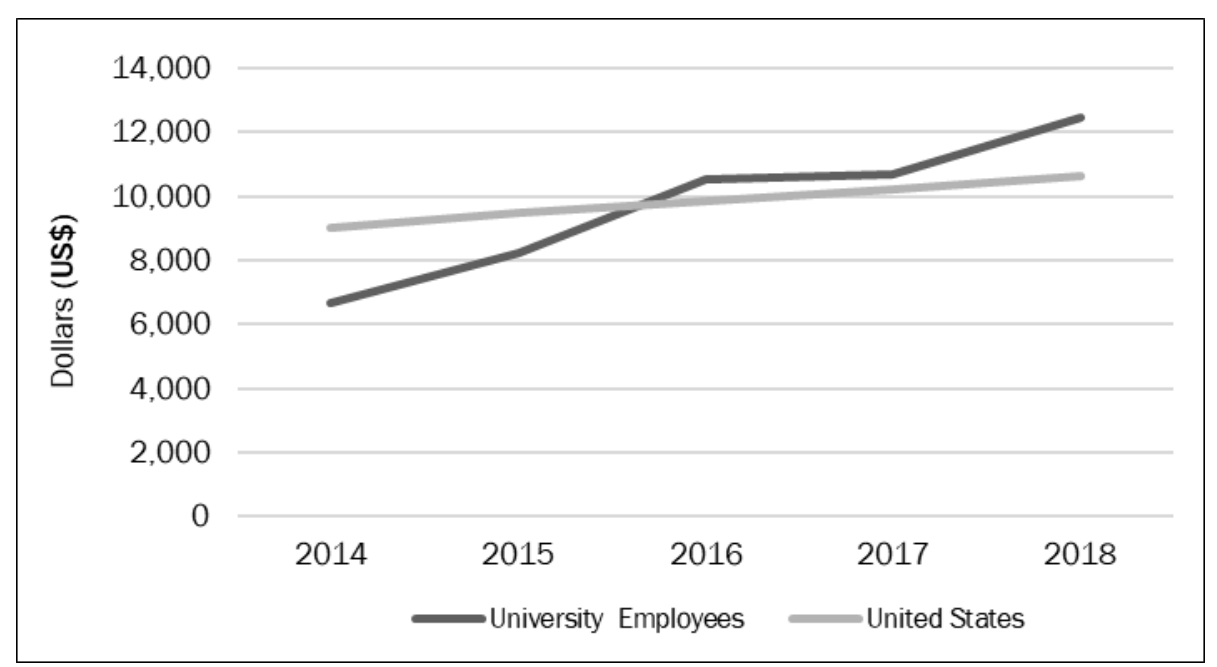


programs, growing seasons, and CSA experience levels. We hypothesized that the expanded shareholder population would also perceive behavior changes, although the pattern may differ from the first-time shareholders in the 2015 pilot. We present and qualify our interpretations of these surveybased behavior change results.

Our second research question is whether participation in CSA is associated with any measurable health impacts as measured by changes in medical service usage. We compared anonymized medical claims costs from CSA participants to a control group of nonparticipants over the same time period and from the same employer pool. We hypothesized that shareholders would have statistically different amounts of medical claims costs following CSA participation compared to the control group.

Finally, we consider how different organizational and programmatic resources are relevant to the development of a CSA voucher program. Healthy behavior changes are not automatically assured by simply offering and incentivizing CSA at a workplace. Supplementary programming and administrative structures must facilitate the experience. From our experience with regional organizations developing and implementing voucher models based on our research, we offer suggestions for organizations that may be considering a CSA incentive model.

\section{Literature Review}

Healthcare costs in the U.S., especially compared to other industrial countries, are rising substantially. These costs, which are over $\$ 11,000$ per year per capita (Figure 1), are felt by both citizens and their employers (OECD, 2021). A significant portion of these costs is directly related to diet, both for medical and pharmacy expenditures. Shifts toward vegetable-centric diets have the potential to significantly reduce costs by reducing the incidence of cardiovascular disease (Jones et al., 2019; Kris-Etherton et al., 2020; Martinez-Lacoba et al., 2018), as well as decreasing rates of other chronic diseases (Bechthold et al., 2019; Bellavia et al., 2013; Boeing et al., 2012; Dauchet et al., 2006). Although the American Heart Association recommends five servings of fruit and vegetables per day per person, only about
$9 \%$ of U.S. adults meet this threshold (Bellavia et al., 2013; Lee-Kwan et al., 2017). Given these studies, programs which promote and reinforce produce consumption may have long-term health benefits.

Studies suggest that CSA can be particularly effective in improving vegetable consumption, especially when incentivized through cost-offsets or vouchers (Allen IV et al., 2017; Berkowitz et al., 2019; Cohen et al., 2012; Hanson et al., 2017; Landis et al., 2010; Vasquez et al., 2016; Wilkins et al., 2015). Beyond vegetable consumption, CSAs have been associated with myriad changes in behavior, in part due to the iterative, subscriptionbased format of CSA (Rossi et al., 2017). Shareholders must continually adapt to the changing contents of their produce box as the seasons progress. By being continually inundated with new produce varieties, shareholders must employ different strategies to avoid waste. Shareholders often gain food preparation skills, engage in vegetablecentric meal planning, and visit restaurants less often (Goland, 2002; Perez et al., 2003; Russell \& Zepeda, 2008). They also alter food acquisition strategies. Some researchers have observed shareholders changing shopping habits by purchasing a broader variety of produce, favoring organic items, and spending less time shopping for food (Allen IV et al., 2017; Brown \& Miller, 2008; Durrenberger, 2002; Russell \& Zepeda, 2008).

With observations that CSA can affect healthy lifestyle changes, it is worth considering the contexts in which CSA may be offered and supplemented with programming to improve shareholder usage of and satisfaction with the produce box (Rossi \& Woods, 2020). Workplace wellness programs, in other formats, can lead to positive returns on investment (Baicker et al., 2010; Berry et al., 2010; Chapman, 2012; Parks \& Steelman, 2008). However, very few organizations have programming around healthy eating, apart from weight loss interventions. Programs centered on modifying food consumption behaviors are difficult to deliver as they require continued engagement from the participant and are thus subject to changes in individual motivation. As shareholders pay for at least part of the CSA subscription prior to receiving vegetables, they may be more motivated to 
extract maximum satisfaction from their expenditure. Additionally, as the vegetables keep arriving every week, something must be done with them.

CSAs, then, are unique among wellness options because they involve repeated shareholder engagement over many weeks (20-25 in our locale). This requires a specific approach to meal planning and associated consumer choices. However, due to the seasonality and limited duration of a CSA, there is the potential for shareholders to revert to previous behaviors following the end of the season. While we have yet to determine an optimal research design for understanding potential behavior reversion, we suggest in another publication that parallel consumer food education programs increase the likelihood of shareholder satisfaction and willingness to renew in following seasons (Rossi \& Woods, 2020). Similarly, behavior changes may be reinforced with supplementary programming. Organizations with existing wellness programs may address the limitation of CSA related to seasonality by offering programs related to nutrition and cooking. Thus, CSAs within employer organizations can expand market opportunities for farmers as well as provide shareholders with CSA usage guidance, which may aid yearly retention of shareholders.

CSA, however, is not the most accessible model for acquiring produce. The prepayment structure can act as a disincentive to lower-income households. As lower income is associated with disproportionately poorer health outcomes, CSA may not be reaching those who might best benefit from access to fresh food (Matthew \& Brodersen, 2018). Research on CSA consistently finds participants to be predominantly white and middle/upper class (Durrenberger, 2002; Ostrom, 2007; Perez et al., 2003). CSA also privileges those with the time and ability to attend pick-ups and flexibly use unpredictable products in the box. Therefore, the CSA voucher/cost-share approach is an initial attempt at making CSA more accessible to incomelimited consumers, as well as those who find the CSA model daunting. While our research primarily considers CSA participants in the context of wellness or employer programs, the incentive model can be modified to reach diverse audiences, food environments, and non-employer organizations.

\section{Background of Central Kentucky CSA Voucher Project}

We developed a pilot study at the University of Kentucky in 2015 to examine the potential impacts of CSA on first-time shareholders. To induce participation, we offered a $\$ 200$ voucher to individuals who had never participated in a CSA. In total, we had 95 participants who were selected from a larger pool of interested individuals. Participants were given a pre- and post-season survey in which they evaluated $30+$ metrics of behavior. We observed significant behavior changes across numerous indicators, especially for individuals who rated their health at or below average at the outset of participation (Rossi et al., 2017).

Following this study, we presented our results to the benefits office at our university, and they agreed to fund $\sim 200$ more vouchers in 2016 as a pilot employee benefit program. The original 95 participants from 2015 were invited to participate. Other employees were then randomly selected from a group expressing interest. We again evaluated behavior changes with a similar pre- and postseason survey.

We presented our data to other self-funded employer organizations in the region, and a few agreed to fund pilot CSA voucher programs in 2016 and 2017. All participants were offered the opportunity to take part in similar pre- and postCSA surveys. In 2017, our city government and university both established the CSA incentives as broader employee benefits. The investments by the university and city government were critical to generating regional momentum for other employers to offer CSA participation incentives. These decisions were in part based on preliminary evaluations of survey data related to employee food lifestyle behaviors as well as CSA participant medical claims data. Expanded sets of these data serve as the foundation for our analysis in this paper.

During the 2016 season, we began working with a community development LLC to facilitate CSA incentive program promotion to new employers. We wanted an independent organization to facilitate the relationship between farmers, employers, and employees, as we expected shareholder voucher participants and their organizations might have a multitude of questions about the voucher 
process and CSA model. Dealing with their concerns seemed especially important due to the expected participation of non-traditional CSA shareholders in an unfamiliar, novel wellness program. The facilitating organization was identified as a mediator between employers and farmers, to ensure both sides were not inundated with questions that the other might be more qualified to answer. The facilitator also was tasked with working out efficient administrative and financial infrastructures for facilitation. After the 2017 season, it became clear that the existing model was not working, and voucher facilitation was transferred to a statewide farmer advocacy organization. This gave more decision-making control over the program to the farmers participating in the voucher program.

Going into the 2020 season, 13 separate employers in our area funded $\sim 1,300$ CSA vouchers for their employees. At the start of our pilot in 2015 , there were $\sim 800$ total CSA shares in our region, none of which were incentivized. In short, impact data from our voucher program provided compelling evidence to employers to offer incentives to their employees to become CSA shareholders. This paper presents key findings of this program to researchers and practitioners interested in a similar approach. In the following two sections, we discuss results from two distinct data types: self-reported behavior changes from pre- and post-CSA survey, and changes in the cost of medical claims for participants in CSA incentive programs. We present the methods, results, and analysis for each data type independently, since each type was gathered through a very distinct approach. We compartmentalize our analysis of each data type to ensure that shareholder behavior changes are considered fully before moving on to their medical claims data, which are quite different. As both data types represent potential and parallel CSA impacts, we discuss them together in the discussion section.

\section{How Does CSA Impact Shareholder Behavior? An Analysis of Survey-Based Food Lifestyle Changes}

First, we discuss behavior changes that parallel participation in the various employer voucher programs in our region. These changes are selfreported and based on a survey methodology. We present the data collection methods first, followed by a longer section that describes and analyzes the results.

\section{Methods for the Lifestyle Changes Survey}

Participants in CSA voucher programs between 2015 and 2018 were given the option to complete a pre-CSA and post-CSA survey for a small incentive. The pre-CSA survey was offered each year in May. The post-CSA survey was offered in each November following program completion. Each survey had the same questions to compare behavior before and after the CSA season. (Some individuals participated in the CSA program in multiple years; in these cases, we only included responses for their first year of participation.) The number of survey participants from each year was: 2015 ( $N=93), 2016$ ( $N=150), 2017$ ( $N=227), 2018$ $(N=276)$. A total of 746 unique individuals completed both the pre- and post-CSA surveys, a 70\% response rate from all voucher participants in these employer programs.

Table 1 includes the 22 behavior variables for which we present survey results in this section. These variables are based on a literature review of the relationship between CSAs and potential behavior change. While our literature review above describes the areas of behavior change often considered by researchers when measuring the impact of CSA and food systems, a detailed description of the survey development can be found in our previous publication (Rossi et al., 2017). We designed these questions to measure the frequency of behaviors such as vegetable consumption and meal preparation that other researchers previously observed CSA to impact.

Table 1 includes the question text for pre- and post-CSA surveys as well as the values respondents could select for each question. For most questions, we asked participants to rate their frequency of behavior over a set period of time (per week, month, or year). For vegetable consumption, we asked about daily intake. A set of questions asked them to agree or disagree with statements about recent changes to behavior. These questions were measured on a 5-point Likert scale. 
For the per week, month, and year frequency questions, we used paired sample t-tests to compare the mean difference in responses of each individual before (May) and after (November) each CSA season, to determine whether there was a sta- tistical change in perception of behavior frequency after participation in the CSA. We also used paired $t$-tests to measure differences in daily fruit and vegetable consumption. We applied this test across the whole participant sample and present the results in

Table 1. Pre- and Post-CSA Survey Question Descriptions

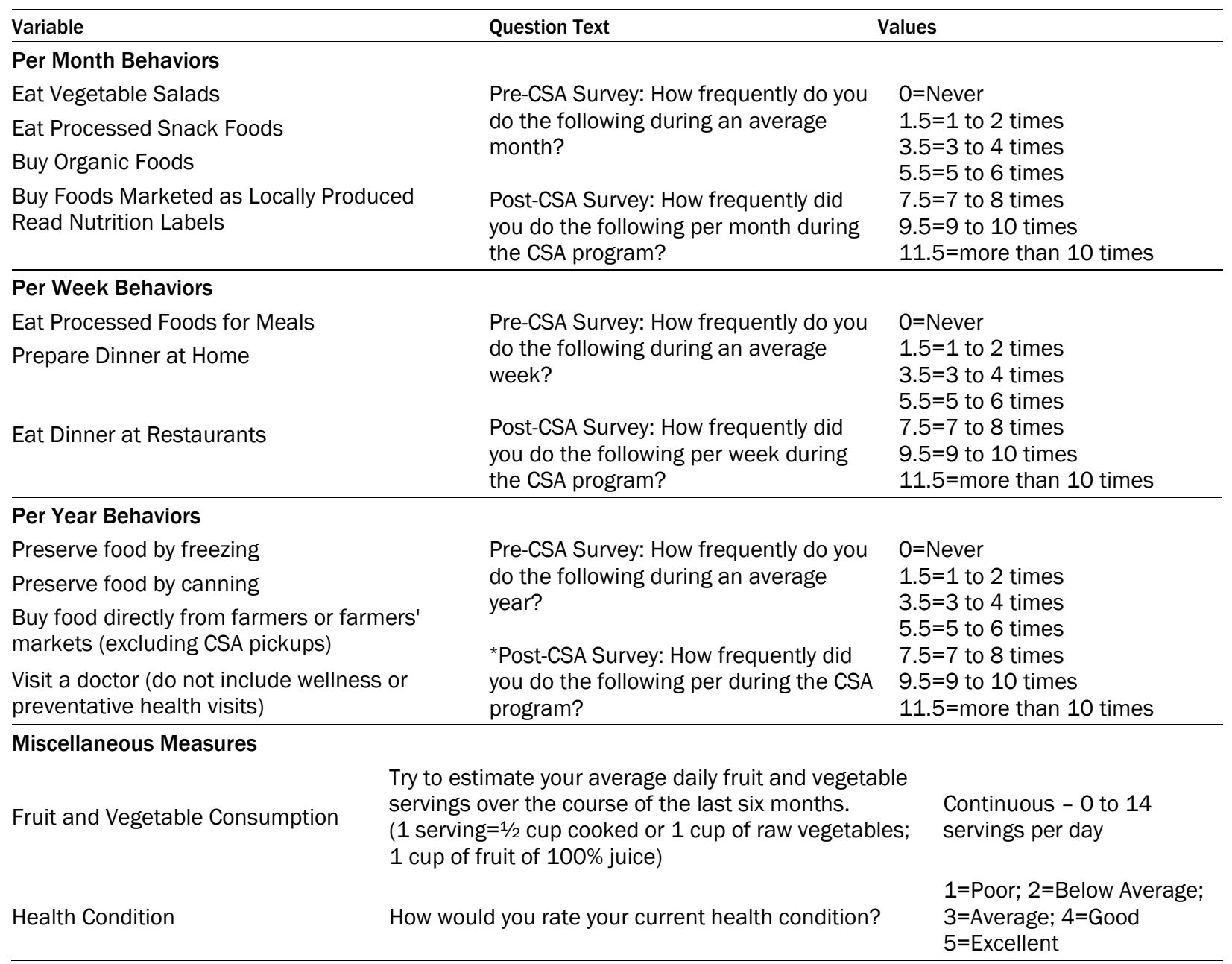

\section{Perceptual Measures}

I pay attention to food sources and farming

I consume processed food regularly

I am happy with my weight

I engage with peers in conversations about food

I have good digestive health

Do you agree or disagree with the following statements?

\author{
1=Strongly Disagree \\ $2=$ Disagree \\ $3=$ Neutral \\ 4=Agree \\ $5=$ Strongly Agree
}

I have recently gained cooking skills

I have adequate energy to complete daily tasks

I usually have a positive mood

Notes: * The CSA duration was approximately six months. We recoded responses for the post-CSA survey by doubling the value to match the duration of the response in the pre-CSA survey. Additionally, we recoded categorical variables for behavior frequency into continuous variables defined by the mid-point of the ranges in the original variable. See the 'Values' column for details. 
Table 3 , with the mean post-CSA minus pre-CSA frequency changes.

In addition, we segmented the full sample into two groups based on individuals' responses to the 'Health Condition' question. The lower health (LH) group is composed of individuals who answered 'poor' or 'below average' to the question "How would you rate your current health condition?" The higher health $(\mathrm{HH})$ group includes those who answered 'average,' 'good,' or 'excellent.' We compared perceptions of behavior frequency within the segments using $t$-tests in the same manner as above. The results are also presented in Table 3. Based on a previously published analysis of 2015 pilot data, we had considered that the LH group might observe their behaviors to change more substantially. With a larger sample size, over more growing seasons (2015-2018), and with a more diverse participant pool, we are able to evaluate this consideration more carefully.

We conducted Wilcoxon signed-rank tests on the questions related to perceptual measures and self-reported health condition, since these questions are measured on a 5-point Likert scale. The Wilcoxon test determines whether the median responses to the question in the pre- and post-CSA surveys are statistically different. It also indicates the direction of change for paired responses; a positive change would be an overall shift in responses from the 'disagree' to 'agree' range of the response. We employ the same test with the question about overall health condition.

\section{Results and Analysis of the Lifestyle Changes Survey}

Survey participants from our CSA incentive programs generally are female, about 43 years old, and have a household income of about $\$ 110,000$ (Table
2). Sixteen percent of participants assessed their health to be poor to below average, i.e., the lower health $(\mathrm{LH})$ shareholder group. Demographics are similar when segmented by self-assessed health.

Table 3 shows the results of the paired $t$-tests, which illustrate differences in perceptions of behavior change between pre- and post-CSA intervention groups. The 'Post-Pre Difference' column is the mean difference in perceived behavior change for individuals within that group. Individuals' responses are only included if they have both a pre- and post-CSA response, since individuals are compared to themselves.

First, we examine all shareholders regardless of their self-assessed health condition (i.e., 'All Shareholders' column). In general, participants in the CSA programs perceived a number of changes. Regarding processed and fresh food indicators, shareholders observed a monthly increase of vegetable salad consumption and a decrease in processed snack food. They also felt that daily vegetable and fruit consumption was increasing slightly, while observing processed meal consumption to decrease by nearly one meal per week.

Shareholders estimated vegetable consumption at 4.3 servings per day (not shown in Table 3) prior to participation. This level is relatively high compared to the national average, so it is not entirely surprising that the perceived magnitude of change post-CSA is not very high. Shareholders may be joining CSA because they already enjoy vegetables and see this as an opportunity to get better quality farm products. It is also possible that participants are simply overestimating pre-CSA consumption. In addition, this current data set includes experienced shareholders who started in 2016 (as opposed to exclusively first-time shareholders as in 2015), so the more

Table 2. Demographics for Survey Participants: All Shareholders and Shareholders by Self-Assessed Health

\begin{tabular}{lccc}
\hline & All Shareholders & $\begin{array}{c}\text { Lower Health (LH) } \\
\text { Shareholder Segment }\end{array}$ & $\begin{array}{c}\text { Higher Health (HH) } \\
\text { Shareholder Segment }\end{array}$ \\
\hline$N$ & 746 & 119 & 627 \\
Age & 42.6 & 43.1 & 42.5 \\
Sex (\% female) & $71 \%$ & $78 \%$ & $70 \%$ \\
Household Income (\$1000) & $\$ 110$ & $\$ 101$ & $\$ 111$ \\
Household Size (Individuals) & 2.4 & 2.4 & 2.4 \\
\hline
\end{tabular}


dramatic changes we observed in our pilot study (Rossi et al., 2017) might be tempered by those who have already achieved an initial positive change.

Shareholders perceived a slight increase in frequency of preparing dinner at home and a slight decrease of meals away from home. In terms of food acquisition strategies, participants reported that they observed buying 'organic' and 'local' foods more often while decreasing their direct purchases from farmers (excluding CSA activities). They also observed an increase in food preservation activities.

We asked shareholders to answer whether or not they agreed with statements that identified a specific change in health and wellbeing (Table 4). Differences in individuals' paired responses to the rating were compared before and after CSA using the Wilcoxon signed-rank test. We represent statistical changes in the median responses of each group with asterisks for significance level and + or - for the directionality of change in magnitude of agreement. In this category, shareholders most strongly agreed with statements related to increased cooking skills, good digestive health, and peer engagement around issues related to food. They also shifted toward agreeing with statements related to having adequate energy and rated their health higher than in the pre-survey. While respondents had more positive assessments postCSA with the question related to weight, most shareholders disagreed with this metric before and after CSA. Finally, they disagreed more strongly about regularly consuming processed food, which means that they perceived they were consuming less after the CSA.

While the changes above apply broadly, more details emerge when different subgroups of shareholders are compared side-by-side. We segmented the respondent population into lower $(N=119)$ and

Table 3. Perceptions of Behavior Change Frequency Following CSA Participation

\begin{tabular}{|c|c|c|c|c|c|c|c|c|c|}
\hline & \multicolumn{3}{|c|}{ All Shareholders } & \multicolumn{3}{|c|}{ Lower Health Segment } & \multicolumn{3}{|c|}{ Higher Health Segment } \\
\hline & $N$ & Post-Pre & erence & $N$ & Post-Pre & rence & $N$ & Post-Pre & erence \\
\hline \multicolumn{10}{|c|}{ Fresh and Processed Food Consumption } \\
\hline Eat salads a & 739 & 0.9 & $* *$ & 117 & 1.8 & $* *$ & 622 & 0.8 & $* *$ \\
\hline Eat processed snack foods a & 625 & -1.5 & ** & 95 & -1.5 & ** & 530 & -1.6 & $* *$ \\
\hline Eat processed foods for meals ${ }^{b}$ & 744 & -0.7 & $* *$ & 119 & -0.8 & $* *$ & 625 & -0.6 & $* *$ \\
\hline $\begin{array}{l}\text { Fruit and Vegetable } \\
\text { Consumption }{ }^{c}\end{array}$ & 623 & 0.2 & * & 96 & 0.6 & $* *$ & 527 & 0.1 & \\
\hline \multicolumn{10}{|l|}{ Purchasing and Nutrition } \\
\hline Buy organic foods ${ }^{a}$ & 620 & 0.4 & ** & 95 & 1.0 & * & 525 & 0.3 & \\
\hline $\begin{array}{l}\text { Buy food marketed as locally } \\
\text { produced a }\end{array}$ & 621 & 0.5 & $* *$ & 96 & 0.8 & & 525 & 0.4 & $\star *$ \\
\hline Read nutrition labels a & 624 & -0.7 & $* *$ & 95 & -0.6 & $* *$ & 529 & -0.7 & $* *$ \\
\hline Buy food directly from farmers $d$ & 616 & -1.2 & $* *$ & 94 & -0.2 & & 522 & -0.7 & $\star *$ \\
\hline \multicolumn{10}{|l|}{ Food Preparation } \\
\hline Prepare dinner at home $b$ & 745 & 0.1 & $* *$ & 119 & 0.6 & $* *$ & 626 & 0.1 & \\
\hline Eat dinner at restaurants $b$ & 746 & -0.1 & * & 119 & -0.1 & & 627 & -0.1 & * \\
\hline Preserve food by freezing d & 614 & 1.4 & $* *$ & 94 & 2.3 & $* *$ & 520 & 1.3 & $* *$ \\
\hline Preserve food by canning $d$ & 614 & 0.8 & $* *$ & 94 & 0.5 & $* *$ & 520 & 0.9 & $* *$ \\
\hline \multicolumn{10}{|l|}{ Miscellaneous } \\
\hline Visit a doctor & 508 & -0.4 & $* *$ & 78 & -0.5 & & 430 & -0.4 & $*$ \\
\hline
\end{tabular}

Notes: $* p<0.05 ; * * p<0.01$. Post-pre difference is the frequency change of the behavior following participation. The measures for each behavior are: ${ }^{a}$ Times per month; ${ }^{b}$ Times per week; ${ }^{c}$ Daily Servings; ${ }^{d}$ Times per Year 
higher $(N=627)$ health shareholder segments. We used paired $t$-tests to compare perceptions of preto post-CSA behavior frequency for individuals within each segment. We conducted Wilcoxon tests on perceived data for individuals in each segment as well. These results are presented alongside the full shareholder population data in the Lower Health $(\mathrm{LH})$ and Higher Health $(\mathrm{HH})$ columns in Tables 3 and 4.

We first note that perceived fruit and vegetable consumption differs by group (Table 3 ). Shareholders in the LH group observed an increase in fruit and vegetable consumption (0.6 servings per day). HH shareholder observations were not significantly different. The HH segment had a pre-CSA mean of 4.3 servings per day, which is rather high compared to the national average and would be difficult to improve. It stands to reason that if they are evaluating their health as 'good' or 'excellent,' they may be including current vegetable consumption as part of this self-assessment. Both groups perceived strong decreases in monthly processed snack food consumption and weekly processed meal consumption (Table 3). Observed monthly vegetable salad consumption also increases for both groups, but is strongest in the LH segment (Table 3).

The food away from home metrics are somewhat more complicated. Shareholders in the LH group observed an increase in the frequency of dinner preparation at home. However, they did not report any frequency change in visiting restaurants for dinner (Table 3). Both groups agree with the statement 'I have recently gained cooking skills' (Table 4). Both segments perceive an increase in canning and freezing food. It does appear, then, that CSA influences food preparation habits.

Regarding food acquisition, the LH segment perceived increased purchasing of organic food while the HH group observed no change (Table 3). The LH change squares with their increased agreement with the statement 'I pay attention to food sources and farming' (Table 4). The HH shareholders did report increased purchasing of locally produced food while also perceiving a decrease in the number of times they made purchases directly from farmers (Table 3). It is possible that shareholders are replacing direct market purchases (e.g., from farmers markets) with CSA products. They may also be acquiring supplementary local products from other outlets (e.g., specialty retail). These relationships suggest that CSA has a complex impact on shareholder food acquisition choices.

In the perceptual metrics, the LH group expressed increased agreement for all categories except 'I consume processed food regularly.' These perceived changes could be explained by shareholders undertaking general changes to their life-

Table 4. Change in Disagreement/Agreement with Statements Following CSA Participation

\begin{tabular}{|c|c|c|c|c|c|c|}
\hline \multirow[b]{2}{*}{ I pay attention to food sources and farming } & \multicolumn{2}{|c|}{ All Shareholders } & \multicolumn{2}{|c|}{ Lower Health Segment } & \multicolumn{2}{|c|}{ Higher Health Segment } \\
\hline & & & + & ** & + & ** \\
\hline I consume processed food regularly & - & $* *$ & & & - & ** \\
\hline I am happy with my weight & + & $* *$ & + & ** & + & ** \\
\hline $\begin{array}{l}\text { I engage with peers in conversations about } \\
\text { food }\end{array}$ & + & ** & + & ** & + & $* *$ \\
\hline I have good digestive health & + & ** & + & ** & + & ** \\
\hline I have recently gained cooking skills & + & ** & + & ** & + & ** \\
\hline I have adequate energy to complete daily tasks & + & $* *$ & + & $* *$ & + & $* *$ \\
\hline I usually have a positive mood & + & * & + & ** & & \\
\hline $\begin{array}{l}\text { How would you rate your current health } \\
\text { condition? }\end{array}$ & + & $* *$ & + & $* *$ & + & ** \\
\hline
\end{tabular}

Notes: All variables except for 'health' rated agreement with a statement about changes in perception (1=Strongly Disagree to $5=$ Strongly Agree). Health is a self-perception of condition ranging 1-5 (i.e., Poor to Excellent). See Table 1 for full questions. * $p<0.05 ; * \star p<0.01$ 
style beyond CSA. As such, we can only assert that the CSA experience exists alongside a number of other changes. The HH group also experienced similar perceptual changes. Finally, in regard to self-perceived health condition, both segments perceived a positive change in health state. In short, shareholders in both health categories perceive CSA to be broadly impactful on their behaviors.

\section{How Does CSA Impact Shareholder Health? An Analysis of Changes in Medical Claims Costs}

We present methods, results, and analysis for a study of medical claims of selected CSA shareholders from the University of Kentucky voucher program. These data, compared to the survey results prevented above, are unique and require a different analytic approach. Then we present a discussion section in which we evaluate CSA impacts more broadly, considering medical claims results alongside survey-based behavior change data as well as testimonials from participating shareholders.

\section{Methods for Medical Claims Costs Analysis}

Self-reported behavior data can provide some insight into the wellbeing of individuals, even if it is just aspirational. As noted, local employer organizations found behavior change data from our 2015 pilot to be compelling, but also wanted to know if there was clear return on investment from a $\$ 150$ 200 per employee voucher. Fortunately, we had access to medical claims data from participants in our university's CSA benefit program, the largest voucher provider in our region. These data allowed us to explore whether billed medical claims paralleled perceived behavior changes.

Our approach was to measure differences in billed medical claims between CSA participants and a control group. We worked with the University benefits office to identify CSA shareholders (test) and non-shareholding employees (control) who had given advanced permission to have anony- mized data used in research. We pooled shareholders from the 2015 and 2016 CSA programs to serve as a test group. For participants in the 2015 CSA program, the threshold between the pre- and postCSA period was defined as September 30, 2015.

For the 2016 CSA participants, September 30, 2016 was the threshold between pre- and post-CSA. For the control group, we used the same threshold as in the 2015 cohort. We included the six-month CSA duration as part of each pre-CSA interval since we expected a lag between intervention and biophysical response as measured by medical claims. At the time of analysis, we had two years of pre- and post-CSA medical claims for 251 employees who participated in a CSA during 2015 and 2016. We also had two years of pre- and post-CSA data for $\sim 3600$ non-participating employees to act as a control group. Participants in both groups were on average 43 years old with the same ratio of females to males (2.6 to 1$)$.

With these data, we calculated the average difference in annual billed medical claims for each individual by subtracting pre-CSA from post-CSA claim amounts. ${ }^{1}$ We then generated the mean pre/post difference for individuals within the pooled CSA participant (test) and CSA nonparticipant (control) groups. Finally, we conducted two-tailed $t$-tests to compare the mean billed differences between the test and control groups. We wanted to determine whether mean differences in post- minus pre-CSA claims differed between the groups. Prior to these analyses, we removed the top and bottom $1 \%$ of pre-/post-CSA billed claim differences from our dataset to limit the impact of outliers.

We conducted our $t$-tests as described above for three different types of claims: (1) all billed medical claims, (2) diet-related medical claims, and (3) diet-related pharmacy claims. The first category of claims included all medical claims, representing the full medical service usage of individuals in both groups. The second and third type of claims were a

\footnotetext{
${ }^{1}$ Because not all individuals were employed for two full years pre- and post-CSA, we generated an annual expenditure for the pre- and post-CSA periods based on the three-month intervals in which they were fully employed. For example, if someone was employed for 15 months prior to CSA participation, the annual expenditure was based on the average billed amount for those five three-month periods multiplied by four. We were only given billed claims if the individual was fully employed over each three-month duration. This was the minimum interval for which we could receive employment data and still have the claims considered anonymized.
} 
subset of the total and were specifically related to diet. We consulted with public health experts to identify specific claim codes related to medical diagnoses and pharmacy prescriptions that might be expected to change with increased vegetable consumption. These conditions included services related to hypertension, obesity, and diabetes. Once these codes were identified, we marked specific claims (and their billed amounts) containing these potentially diet-related codes. ${ }^{2}$ This eliminated claims related to physical trauma, chronic conditions, chemotherapy, and other medical issues either unrelated to diet or not to be expected to change with diet modification. We cross-referenced these claims with their associated procedures codes to eliminate any claims related to catastrophic events such as expensive emergency surgeries that would skew costs dramatically.

\section{Results and Analysis for Medical Claims Costs Analysis}

While measuring behavior changes in CSA is important, whether these perceived changes translate into biophysical impacts is an open question. We evaluated whether changes in billed medical claims differ in magnitude when comparing CSA shareholders to non-participants from the same employee pool. We present results while qualifying and contextualizing these data, as we are collecting longer-term data and developing more complex analytic models. The following results, then, should be treated as preliminary in regard to the potential health benefits of CSA.

In Table 5, we present the results from $t$-tests comparing pre-/post-CSA differences in billed claim amounts ${ }^{3}$ between the test and control groups. These data allow us to compare whether changes in claims after a specified date are statistically different depending on whether someone participated in a CSA. ${ }^{4}$ The mean differences (mean diff) columns represent the average annual difference in billed claims pre- and post-CSA for the test or control group. ${ }^{5} \mathrm{~A}$ positive difference means that billed amounts increased after CSA participation, or after the date used to delineate pre- and postintervals for the control group. The 'group difference' column is the difference between groups with respect to their pre-/post-CSA expenditure differences. Positive figures in the 'group difference' column indicate that billed claims increased more for the control group compared to the test group.

When comparing the changes in total billed amounts between the groups (Table 5, Row 1), the differences are not significant; the increases in billed amounts for both groups are not statistically different. This lack of difference is not surprising, because the total billed claims category includes all claims regardless of their potential relationship to diet. Physical trauma, routine check-ups, surgery, and diagnostic imaging are included in the data and are likely to obscure any changes in diet-related expenditures.

When we compare group mean differences for diet-related claims only, the CSA group appears to be billed annually $\$ 201$ less in diet-related physician and hospital services than the control group (Table 5, Row 2). This difference between groups is statistically significant. The control group's claims costs appear to increase relative to the claims of CSA shareholders. This result suggests that CSA participation may impact diet-related medical claims.

Both groups show increases in diet-related pharmacy claims over time (Table 5, Row 3). The magnitude of these increases, however, is not sta-

\footnotetext{
${ }^{2}$ We used ICD-9 and ICD-10 codes, which are standard diagnosis codes for clinics and hospitals. Visits are billed to insurance companies based on a combination of these diagnosis codes and associated procedure codes.

${ }^{3}$ We used the field 'billed expenses' from the medical claims in order to avoid having to determine the rate negotiated between the service provider and the insurance company. As most participants were using the same medical system, the billed expenses should be relatively constant.

${ }^{4}$ We pooled participants from the 2015 and 2016 CSA programs to serve as a test group. As individuals in the control group did not participate in the CSA, we designated a date to delineate 'before' and 'after' intervals. We used the same cutoff date as we did for the 2015 CSA cohort. The pre-CSA period for the 2015 CSA cohort and the control was defined as 10/1/2013-9/30/2015. The postCSA period was 10/1/2015-9/30/2017. For the 2016 CSA participants, 9/30/2016 was the cutoff date between pre- and post-CSA. ${ }^{5}$ We calculated the average expenditures differences for three-month intervals across a maximum of two years pre- and post-CSA. We received claims data only if an individual was insured for the full duration of each interval.
} 
Table 5. Annual Differences in Billed Medical Claims for CSA Participants and Non-Participants

\begin{tabular}{lcccccc}
\hline & \multicolumn{2}{c}{$\begin{array}{c}\text { Nonparticipants } \\
\text { (Control Group) }\end{array}$} & \multicolumn{2}{c}{$\begin{array}{c}\text { CSA Participants } \\
\text { (Test Group) }\end{array}$} & \multicolumn{2}{c}{ Between Group t-test } \\
\cline { 2 - 7 } Claim Type & $\boldsymbol{N}$ & Mean Diff (SE) & $\boldsymbol{N}$ & Mean Diff (SE) & Group Difference & $p$-score \\
\hline Total Billed Claims & 3,033 & $\$ 1674(215)$ & 251 & $\$ 1281(750)$ & $\$ 393(777)$ & 0.61 \\
Diet-Related Medical Claims & 3,005 & $\$ 199(29)$ & 250 & $-\$ 2(103)$ & $\$ 201(106)$ & $0.05 *$ \\
Diet-Related Pharmacy Claims & 3,022 & $\$ 79(7)$ & 249 & $\$ 63(23)$ & $\$ 16(27)$ & 0.55 \\
\hline
\end{tabular}

Note: * $p<0.05 ; * * p<0.01$

tistically different when comparing groups. In this type of claim, which is specific to diet-related medications (i.e., obesity, hypertension, type- 2 diabetes), there is no obvious short-term benefit to CSA participation. The two groups are similar in terms of increases in billed amounts.

These various medical and pharmacy claims suggest some initial insights. Both groups show steady increases in total medical claims (also suggested by Figure 1) and pharmacy claims. These differences are statistically similar in magnitude. However, diet-related medical claims increase at a greater rate for the control group than for CSA shareholders. It seems that diet-related claims costs for CSA participants remain steady while costs for non-participants increase. While this initial analysis presents some evidence that CSA has an impact on diet-related health outcomes, we will consider a few reasons for pause in the discussion section. Again, we are developing further analytic approaches to test and verify these results, so they should be considered preliminary.

\section{Discussion}

In the data presented, we observed that CSA shareholders perceive changes in behavior following participation in an employer-sponsored voucher program. These perceptions parallel voluntary feedback we received from participants in these programs. We present some of these open-ended responses from the post-CSA surveys to help contextualize our quantitative data.

First, many participants connected behavior changes with the volume of produce received. Shareholders were extremely concerned about wasting items from their produce box. In many cases, they complained about the overwhelming volume of certain items in their box. Kohlrabi, kale, and squash often were the culprits. However, once they adjusted to this situation, participants noted that waste avoidance was a motivator. For example, "This program has definitely increased our vegetable intake and we have tried several new recipes. Our goal is to not let anything go to waste, so we have to work hard to not have any leftover veggies at the end of each week." Another participant had a stronger sentiment:

This was a life-changing experience for me, actually somewhat emotional. I LOVED driving by the farm knowing that was MY food being prepared. It opened my eyes to foods I had never experienced before. As a frugal person who avoids waste, the experience 'forced' me to plan ahead and experiment with my food. I liked the recipes, tried several of them and appreciate instructions on storage.

The connection between waste avoidance and creative food preparation may have been a key motivator for many behavior changes. One shareholder likened CSA to "solving a puzzle each week." The unpredictable contents of the box presented a unique challenge. One participant stated that the CSA "renewed my interest in canning and preserving. ... I had to do SOMETHING with all that food."

These sentiments suggest that the repetitive pattern of CSA provided an experience that required modifications to typical food purchasing and consumption patterns. By providing a large amount of produce on a weekly basis, the entire food environment of a household shifts. As one participant states, "During the delivery months, I 
am less likely to eat at restaurants because I already have food to prepare at home. Not only is it a better quality but I don't want to waste it. It also allows me to try to prepare things I might normally not buy." Another shareholder states, "The increase in organic and local fruits and vegetables has helped cut down on grocery spending and boosts my family's interest in fruits and vegetables."

Here we see echoes of the quantitative results presented in Tables 3 and 4, in which the full shareholder sample showed an increased frequency in purchasing organic and local foods and in consuming vegetables daily. Upon experiencing CSA, many shareholders may see more value in alternative food networks in general. The specific reasons for changing food acquisition strategies may be an area for further research. In other words, for whom and to what extent does CSA participation alter food purchasing patterns? Surprisingly, CSA participation is only associated with small quantitative increases in frequency of dinner preparation (Table 3), even as participants in both groups perceive their cooking expertise to have improved (Table 4). Nevertheless, the qualitative commentary from shareholders is firmly on the side of a shift toward more food at home. The connection between food preparation and health is clearly articulated by a first-time shareholder:

Working with a CSA has made the entire family more willing to eat healthy. The kids enjoy going through the bag every week to see what we have gotten and are more willing to try foods that have those fruits and vegetables in them. In an attempt to make sure that we don't waste any of the CSA items, my husband and I have also been eating a lot healthier. Searching for recipes to cook veggies that we wouldn't normally eat has been a lot of fun.

Others stated in open-ended responses that CSA participation had a broader social benefit. They discussed sharing excess produce with neighbors and coworkers, engaging in meal swaps, and attending potlucks. While COVID-19 may make meal sharing less viable in the short-term, it is providing more motivation for individuals to cook at home and to buy directly from producers. These influences may make CSA more accessible in the long run. A point that is less speculative, however, is that CSA participants view the experience as providing motivation to modify their relationship to food. For instance, perceptual metrics (Table 4) show that LH and $\mathrm{HH}$ shareholders gained knowledge of food sourcing and engaged more frequently with peers about food.

While the specific reasons for these evaluations requires further study, the general perception of shareholders is that CSA impacts their food lifestyle behaviors in a positive way. This positive evaluation is important when considering a CSA incentive as a wellness option because participants are able to identify and articulate the perceived benefits of their participation. Some shareholders felt that CSA-related behavior changes were directly benefiting their health. As one participant noted:

After a recent annual physical, my doctor noted that I had high cholesterol and needed to make adjustments to my diet. He recommended eating a variety of colorful fruits and vegetables as a way to improve health. I like the CSA because incorporating these fruits and vegetables into my diet is essentially automated. Someone selects a variety of produce, it arrives at work, and that convenience has really helped me implement this health goal. My health metrics improved at the last checkup. The CSA shares delivered to my work removed many barriers to entry.

The CSA incentive, especially in work-place scenarios, can provide an on-ramp for individuals to make changes in their own behaviors. Participants' self-perception that they are doing something that contributes to their longer-term wellbeing may support or reinforce broader lifestyle changes. Perceptual indicators (Table 4) do support the idea that some shareholders perceived the experience in CSA to be impactful in many wellness-related areas, such as digestive health, mood, energy, and general health level. That these programs also make CSA participants have a more positive view of their employer or benefits pro- 
gram can also lead to better satisfaction with the workplace environment. ${ }^{6}$

Positive behavioral changes can potentially lead to quantifiable improvements in health if individuals maintain these changes. Our analysis of medical claims is an attempt to consider short-run impacts of these programs, since employers who fund CSA incentives are keenly interested in potential cost savings. Our research points to the possibility of CSA having some measurable financial impacts in terms of participant medical claims. We have seen statistically significant decreases in dietrelated billed claims for CSA participants compared to the control group. While these data are compelling, we suggest that much more work be done to ascertain the impact of CSA on medical claims.

Human health and physiology is complex, and the duration of behavior change required to see long-term health changes reflected in billing patterns is likely longer than the two-year pre- and post-CSA intervals we employed in this analysis. Additionally, billed claims may fluctuate in a way that increases or decreases over a longer term. It may be that CSA participants' medical usage is cyclical, and we captured a moment in time where there was a decrease. Nevertheless, as of 2021 the CSA voucher program is continuing. We will eventually have the ability to analyze multiple years of claims data for each participant. With longer-term data and an expanded shareholder population, we may be able to provide more clarity about the CSA impact through more complex econometric analyses.

Behavioral and perceptual data from surveys (Tables 3 and 4) suggest that certain behavior changes are perceived more strongly by shareholders who began their CSA in a lower health category. Wellness programs, then, may receive a better return on their investment if they target potential participants who are not already in a high health category. In our claims data, many shareholders had billed claims prior to participation that were quite low, sometimes near zero. Our shareholder population is likely a healthier subset of the overall employee population. A more complete and generalizable analysis would have more individuals that meet criteria as higher risk patients. However, we had no way to match the 'lower-health' shareholders from our survey analysis to participants in the claims analysis, since the latter were anonymized.

Our Health and Wellness Organization attempted to limit recruitment to the CSA voucher initially (in 2015 and 2016) to those with a health profile that would likely benefit from increased vegetable consumption. Many of these higher-risk individuals were less interested in joining the CSA. Health and Wellness eventually relaxed their criteria to include lower-risk employees. Developing strategies to diversify the subscriber base in terms of health is a critical, yet quite difficult challenge that employer-support organizations have not yet solved.

While employers are interested in knowing whether CSA can reduce medical claims, it is not feasible to say more than that there exists a possibility that CSA can have an impact. Whether CSA participation on its own has a tangible, quantifiable (e.g., vis-à-vis medical claims) health benefit, however, is somewhat beside the point. Our main contribution is to outline an approach to evaluate medical claims changes in relation to CSA-related employer programs since behavioral and perceptual data suggest that participants see value in CSA for their health. Physiological change may be possible to observe, however a more robust evaluation would require a larger, continuously enrolled shareholder population that started CSA with higher initial medical claims. As our incentive program expands and diversifies its subscriber base, we may be able to identify participants who fit these conditions and can provide a better sense of long-term CSA impact.

\section{Conclusion: Organizational Considerations for CSA Incentive Success}

Over the course of our overall research, we have observed CSA benefits to individuals, communi-

\footnotetext{
${ }^{6}$ We included a few questions in our survey about employer perception and satisfaction, though we have not included the formal results in our tables. On average, however, the CSA incentive program improves the employees' view of their employer and associated benefits offerings.
} 
ties, and organizations through different types of data. However, the relative success of an incentive program involves more than simply giving someone a voucher and telling them to choose a CSA farm. The CSA approach, as noted, is quite different from typical food acquisition channels. It requires learning and time management in different areas, such as seasonal food preparation and shopping for supplementary meal ingredients. These requirements (as well as the up-front payment) will tend to exclude individuals who do not have flexibility to alter their food acquisition strategies and finances. If a new consumer makes the jump to CSA, they might find the model ill-suited to their needs, skills, or preferences. Thus, specific social and institutional supports are critical to making a CSA incentive program work and allow individuals to derive benefits from it. Because these programs may be more appealing to individuals who are already eating vegetables and have healthier lifestyles, an effective incentive program requires innovative recruitment strategies that focus on lower-health individuals as well as in-season shareholder education programs.

Our partner organizations had a number of strategies to engage new shareholders. Recruitment focused on providing an overview of the CSA concept for employers (e.g., benefits personnel, wellness coordinators, etc.) and potential shareholders who were unfamiliar with the model. Innovations such as payroll deduction, which would spread out the employee payment while still paying the farmer up-front, were offered by some employers along with vouchers. These create a less complicated, more financially feasible program for some shareholders. Farms and farm support organizations also held CSA fairs, where potential shareholders could meet CSA farmers, discuss the model structure, and learn about what they might see on a weekly basis. For instance, to emphasize the seasonality of CSA boxes, some farmers used a series of 20-25 pictures of their CSA boxes to show the weekly evolution of the produce box. This type of visual representation helped manage shareholder expectations. However, post-season feedback revealed that many new shareholders were still shocked by how much squash they received in the summer months, while not realizing how late in the season tomatoes emerge. In 2020, in-person CSA fairs were not possible due to COVID-19, so a local-farmer support organization, in conjunction with the state department of agriculture, held a virtual fair. The 'attendance' was at least three times that of the in-person fairs, and the fair suggested some emerging strategies for farmershareholder engagement (Spencer, 2020).

Consumer education programs were critical to maximizing shareholder benefit and satisfaction, and were the cornerstone of how we envisioned various employer-supported programs (Rossi \& Woods, 2020). Depending on the capacity of the specific employer, some workplaces offered programs aimed at improving shareholder experience. Some organizations had a nutritionist or chef conduct live (and recorded) cooking demos. They would take that week's box of produce and create a meal. Others did 'Iron Chef-type competitions with employee contestants. A few offered weekly recipe cards. One larger organization hosted a wellknown local chef to offer some quick cooking tips on greens one might encounter in an early-season CSA box. These programs, which are constantly evolving, focus on strategies for seasonal eating and food preparation.

CSA incentive programs are difficult to establish initially and require a highly effective pointperson within that organization or employer. Sometimes this is a dedicated employee who is passionate about CSA; sometimes, a wellness professional who sees value in offering a food-related employee benefit. These individuals can facilitate work-place drops, promote CSA to peers who are unfamiliar to the concept, make connections with farmers, and campaign to get benefits directors to approve an incentive program. They also can offer or organize supplementary programming in-season, poll peers on their pre-season interest in CSA and post-season satisfaction, and promote the model to friends in other organizations and workplaces. A successful incentive program requires farmers or farm support organizations to identify the person within an organization who has a direct line to potential funding sources for that benefit. While the employee benefits director might be this person, that is not always the case. There is no set playbook for engagement, as each organizational 
hierarchy of influence differs. To reiterate, finding an internal champion within an organization is the first critical step in establishing a long-term CSA incentive program.

Establishing effective technical assistance networks or farmer support organizations is critical to long-term success of incentivized CSA programs. Experienced farms help lend legitimacy to the CSA by providing consumers with a high-quality experience. The farmer-centric organization that manages our voucher program directly engages employer organizations to promote the CSA concept and the incentive model. It has developed different engagement strategies, depending on the type of employer, which are constantly evolving. Its role in expanding consumer consciousness of CSA is important, and it helps shield the farms from the typical questions of first-time shareholders by providing consumer-facing resources for CSA usage. In addition, as a liaison with employers and their wellness initiatives, the organization acts to transfer innovations around in-season programming and shareholder engagement. It helps identify, vet, and on-board new farms based on the standards set by their advisory board to bring CSAs into the fold.

As voucher program facilitators evolve, their innovations will have broader resonance, especially those that are responding to the COVID pandemic. By connecting with CSA support organizations across the U.S., such as the CSA Innovation Network (csainnovationnetwork.org), they can learn from and promote models to others who are working to expand local food systems. As national knowledge networks or 'communities of practice' develop and expand-in part because of the COVID response-we hope that innovations such as the CSA incentive programs we describe might serve to inspire and build consumer awareness of and engagement with farmer initiatives in various local food sectors.

\section{References}

Allen IV, J. E., Rossi, J., Woods, T. A., \& Davis, A. F. (2017). Do community supported agriculture programmes encourage change to food lifestyle behaviours and health outcomes? New evidence from shareholders. International Journal of Agricultural Sustainability, 15(1), 70-82. https://doi.org/10.1080/14735903.2016.1177866

Baicker, K., Cutler, D., \& Song, Z. (2010). Workplace wellness programs can generate savings. Health Affairs, 29(2), 304311. https://doi.org/10.1377/hlthaff.2009.0626

Bechthold, A., Boeing, H., Schwedhelm, C., Hoffmann, G., Knüppel, S., Iqbal, K., De Henauw, S., Michels, N., Devleesschauwer, B., Schlesinger, S., \& Schwingshacki, L. (2019). Food groups and risk of coronary heart disease, stroke and heart failure: A systematic review and dose-response meta-analysis of prospective studies. Critical Reviews in Food Science and Nutrition, 59(7), 1071-1090. https://doi.org/10.1080/10408398.2017.1392288

Bellavia, A., Larsson, S. C., Bottai, M., Wolk, A., \& Orsini, N. (2013). Fruit and vegetable consumption and all-cause mortality: A dose-response analysis. American Journal of Clinical Nutrition, 98(2), 454-459. https://doi.org/10.3945/ajcn.112.056119

Berkowitz, S. A., O'Neill, J., Sayer, E., Shahid, N. N., Petrie, M., Schouboe, S., . . Bellin, R. (2019). Health center-based community-supported agriculture: An RCT. American Journal of Preventive Medicine, 57(6, Suppl. 1), S55-S64. https://doi.org/10.1016/i.amepre.2019.07.015

Berry, L., Mirabito, A. M., \& Baun, W. (2010 December). What's the hard return on employee wellness programs? Harvard Business Review, 88(12), 104-112, 114. https://hbr.org/2010/12/whats-the-hard-return-on-employee-wellness-programs

Boeing, H., Bechthold, A., Bub, A., Ellinger, S., Haller, D., Kroke, A., Leschik-Bonnet, E., Müller, M. J., Oberritter, H., Schulze, M., Stehle, P., \& Watzl, B. (2012). Critical review: Vegetables and fruit in the prevention of chronic diseases. European Journal of Nutrition, 51(6), 637-663. https://doi.org/10.1007/s00394-012-0380-y

Brown, C., \& Miller, S. (2008). The impacts of local markets: A review of research on farmers markets and community supported agriculture (CSA). American Journal of Agricultural Economics, 90(5), 1298-1302. https://doi.org/10.1111/j.1467-8276.2008.01220.x 
Chapman, L. S. (2012). Meta-evaluation of worksite health promotion economic return studies: 2012 update. American Journal of Health Promotion, 26(4), 1-12. https://doi.org/10.4278/ajhp.26.4.tahp

Cohen, J., Gearhart, S., \& Garland, E. (2012). Community supported agriculture: A commitment to a healthier diet. Journal of Hunger \& Environmental Nutrition, 7(1), 20-37. https://doi.org/10.1080/19320248.2012.651393

Dauchet, L., Amouyel, P., Hercberg, S., \& Dallongeville, J. (2006). Fruit and vegetable consumption and risk of coronary heart disease: A meta-analysis of cohort studies. The Journal of Nutrition, 136(10), 2588-2593. https://doi.org/10.1093/jn/136.10.2588

Durrenberger, E. P. (2002). Community supported agriculture in Central Pennsylvania. Culture \& Agriculture, 24(2), 4251. https://doi.org/10.1525/cag.2002.24.2.42

Freedman, D. A., Choi, S. K., Hurley, T., Anadu, E., \& Hébert, J. R. (2013). A farmers' market at a federally qualified health center improves fruit and vegetable intake among low-income diabetics. Preventive Medicine, 56(5), $288-292$. https://doi.org/10.1016/j.ypmed.2013.01.018

Galt, R. E. (2013). The moral economy is a double-edged sword: Explaining farmers' earnings and self-exploitation in community-supported agriculture. Economic Geography, 89(4), 341-365. https://doi.org/10.1111/ecge.12015

Goland, C. (2002). Community supported agriculture, food consumption patterns, and member commitment. Culture \& Agriculture, 24(1), 14-25. https://doi.org/10.1525/cag.2002.24.1.14

Hanson, K. L., Kolodinsky, J., Wang, W., Morgan, E. H., Pitts, S. B. J., Ammerman, A. S., Sitaker, M., \& Seguin, R. A. (2017). Adults and children in low-income households that participate in cost-offset community supported agriculture have high fruit and vegetable consumption. Nutrients, 9(7), 726. https://doi.org/10.3390/nu9070726

Hayden, J., \& Buck, D. (2012). Doing community supported agriculture: Tactile space, affect and effects of membership. Geoforum, 43(2), 332-341. https://doi.org/10.1016/i.geoforum.2011.08.003

Hinrichs, C. C. (2000). Embeddedness and local food systems: Notes on two types of direct agricultural market. Journal of Rural Studies, 16(3), 295-303. https://doi.org/10.1016/S0743-0167(99)00063-7

Jones, J. P. H., Abdullah, M. M. H., Wood, D., \& Jones, P. J. H. (2019). Economic modeling for improved prediction of saving estimates in healthcare costs from consumption of healthy foods: The Mediterranean-style diet case study. Food \& Nutrition Research, 63. https://doi.org/10.29219/fnr.v63.3418

Kris-Etherton, P. M., Petersen, K. S., Velarde, G., Barnard, N. D., Miller, M., Ros, E., O’Keefe, J. H., Williams, K., Van Horn, L., Na, M., Shay, C., Douglass, P., Katz, D. L., \& Freeman, A. M. (2020). Barriers, opportunities, and challenges in addressing disparities in diet-related cardiovascular disease in the United States. Journal of the American Heart Association, 9(7), e014433. https://doi.org/10.1161/JAHA.119.014433

Landis, B., Smith, T. E., Lairson, M., Mckay, K., Nelson, H., \& O'Briant, J. (2010). Community-supported agriculture in the Research Triangle region of North Carolina: Demographics and effects of membership on household food supply and diet. Journal of Hunger \& Environmental Nutrition, 5(1), 70-84. https://doi.org/10.1080/19320240903574403

Lee-Kwan, S. H., Moore, L. V., Blanck, H. M., Harris, D. M., \& Galuska, D. (2017). Disparities in state-specific adult fruit and vegetable consumption-United States, 2015. Morbidity and Mortality Weekly Report (MMWR), 66(45), 12411247. https://doi.org/10.15585/mmwr.mm6645a1

Martinez-Lacoba, R., Pardo-Garcia, I., Amo-Saus, E., \& Escribano-Sotos, F. (2018). Mediterranean diet and health outcomes: A systematic meta-review. European Journal of Public Health, 28(5), 955-961. https://doi.org/10.1093/eurpub/cky113

Matthew, P., \& Brodersen, D. M. (2018). Income inequality and health outcomes in the United States: An empirical analysis. The Social Science Journal, 55(4), 432-442. https://doi.org/10.1016/j.soscij.2018.05.001

McCormack, L. A., Laska, M. N., Larson, N. I., \& Story, M. (2010). Review of the nutritional implications of farmers' markets and community gardens: A call for evaluation and research efforts. Journal of the American Dietetic Association, 110(3), P399-P408. https://doi.org/10.1016/j.jada.2009.11.023

Organisation for Economic Cooperation and Development (OECD). (2021). Health spending (Indicator). OECD iLibrary. https://doi.org/10.1787/8643de7e-en 
Ostrom, M. R. (2007). Community supported agriculture as an agent of change: Is it working? In C. C. Hinrichs \& T. A. Lyson (Eds.), Remaking the North American food system: Strategies for sustainability (pp. 99-120), University of Nebraska Press. https://wtf.tw/ref/hinrichs lyson.pdf

Parks, K. M., \& Steelman, L. A. (2008). Organizational wellness programs: A meta-analysis. Journal of Occupational Health Psychology, 13(1), 58-68. https://doi.org/10.1037/1076-8998.13.1.58

Perez, J., Allen, P., \& Brown, M. (2003). Community supported agriculture on the central coast: The CSA member experience (Research Brief 1). University of California, Santa Cruz, Center for Agroecology \& Sustainable Food Systems. https://escholarship.org/uc/item/5wh3z9jg

Ridberg, R. A., Bell, J. F., Merritt, K. E., Harris, D. M., Young, H. M., \& Tancredi, D. J. (2019). Peer reviewed: Effect of a fruit and vegetable prescription program on children's fruit and vegetable consumption. Preventing Chronic Disease, 16, 180555. https://doi.org/10.5888/pcd16.180555

Rossi, J., Allen, J. E., Woods, T. A., \& Davis, A. F. (2017). CSA shareholder food lifestyle behaviors: A comparison across consumer groups. Agriculture and Human Values, 34(4), 855-869. https://doi.org/10.1007/s10460-017-9779-7

Rossi, J., \& Woods, T. (2020). Understanding shareholder satisfaction and retention in CSA incentive programs. Journal of Food Distribution Research, 51(3), 16-40. https://doi.org/10.22004/ag.econ.309028

Rossi, J. J., Woods, T. A., \& Allen, J. E. (2017). Impacts of a community supported agriculture (CSA) voucher program on food lifestyle behaviors: Evidence from an employer-sponsored pilot program. Sustainability, 9(9), 1543. https://doi.org/10.3390/su9091543

Russell, W. S., \& Zepeda, L. (2008). The adaptive consumer: Shifting attitudes, behavior change and CSA membership renewal. Renewable Agriculture and Food Systems, 23(2), 136-148. https://doi.org/10.1017/S1742170507001962

Spencer, E. (2020). Virtual CS A fairs (Extension Pub. LSF-IB-01). University of Kentucky, College of Agriculture, Food and Environment. https://lfscovid.localfoodeconomics.com/briefs/virtual-csa-fairs/

Vasquez, A., Sherwood, N. E., Larson, N., \& Story, M. (2016). A novel dietary improvement strategy: Examining the potential impact of community-supported agriculture membership. Public Health Nutrition, 19(14), 2618-2628. https://doi.org/10.1017/S1368980015003638

Wilkins, J. L., Farrell, T. J., \& Rangarajan, A. (2015). Linking vegetable preferences, health and local food systems through community-supported agriculture. Public Health Nutrition, 18(13), 2392-2401. https://doi.org/10.1017/S1368980015000713 